\title{
O Moodle de Lovelace: Um Curso a Distância de Python Essencial, Ativo e Prático para Formação de Programadoras
}

\author{
Márcia Gonçalves de Oliveira, Rutinelli da Penha Fávero, Mônica F. da Silva Lopes, \\ Anne Carolina Silva, Jennifer Gonçalves do Amaral, Helen França Medeiros
}

\author{
${ }^{1}$ Centro de Referência em Formação e Educação a Distância (Cefor) \\ Instituto Federal do Espírito Santo (Ifes) - Vitória - ES
}

\begin{abstract}
Resumo. Uma realidade comum de muitas adolescentes e jovens é a dificuldade ou impossibilidade de continuar os estudos após uma gravidez porque assumirão responsabilidades de cuidar de seus filhos em tempo integral ou de trabalhar para sustentá-los. Com o objetivo de oferecer a essas jovens e a outras estudantes que tenham interesse em aprender programação uma possibilidade de formação profissional a domicílio, desenvolvemos o Moodle de Lovelace, um curso a distância de programação Python com conteúdos essenciais de programação, atividades planejadas com metodologias ativas e aplicações práticas no mundo real. A contribuição deste curso para atrair as jovens mulheres para a carreira de computação é oferecer a cada uma delas a oportunidade de estudar programação de qualquer lugar e em seu próprio tempo.
\end{abstract}

\section{Introdução}

A programação de computadores tem gerado muitas discussões nas comunidades de Educação e de Informática por ser um conhecimento associado às dificuldades de ensino e de aprendizagem [Souza et al. 2016, Oliveira et al. 2017]. No caso das mulheres, além dessas dificuldades, existem as dificuldades de aceitação e de permanência em uma área de conhecimento que, por ter sido predominantemente masculina ao longo dos anos, ainda existem muitos preconceitos e resistências.

Uma vez que a aprendizagem de programação requer a combinação de várias habilidades cognitivas e extensa prática de exercícios, o planejamento de um curso de programação deve contemplar metodologias que favoreçam o desenvolvimento das habilidades da prática da programação e possibilitem a formação de bons programadores.

No caso de cursos a distância, o processo educativo de programação, além de trabalhar as habilidades e ampliar a prática de exercícios, deve ser inclusivo e vencer a distância transacional, que representa um hiato de comunicação entre aprendizes, tutores e professores em decorrência da distância física [Moore 2002].

Dessa forma, com os objetivos de atrair jovens mulheres para a programação e favorecer a aprendizagem de programação por meio de metodologias ativas e de tecnologias digitais, desenvolvemos o Moodle de Lovelace, um curso a distância de Programação Python Essencial, Ativa e Prática direcionado à formação de programadoras.

A ideia de ofertar um curso de programação a distância para jovens mulheres surgiu da observação de uma realidade de muitas meninas do Estado do Espírito Santo: a gravidez na adolescência e na juventude, o que tem impedido muitas delas de iniciarem ou continuarem seus estudos. 
Nos últimos dois anos, 779 garotas entre 10 a 14 anos deram à luz em todo 0 Estado do Espírito Santo e outras 15.8 mil jovens mães têm de 15 a 19 anos ${ }^{1}$. Diante dessa realidade, a Educação a Distância apresenta-se como uma boa oportunidade de formação profissional de qualquer lugar e a qualquer tempo para essas meninas e também para as meninas que buscam ampliar seus conhecimentos de informática.

O curso $O$ Moodle de Lovelace é uma referência ao ambiente virtual de aprendizagem Moodle e uma homenagem à condessa Ada Lovelace, a brilhante matemática filha do Lord Byron, considerada a primeira programadora do mundo. Nesse curso de programação Python são destaques: o uso de metodologias ativas orientadas ao desenvolvimento das habilidades de programação, os fóruns de discussão e de trabalho colaborativo, a tutoria realizada por meninas de um curso de Bacharelado em Sistemas de Informação e a integração de diferentes mídias em um material ativo, prático e atrativo.

A contribuição deste trabalho para o ingresso de mais mulheres nas carreiras de computação é ampliar as possibilidades de formação em programação para mulheres de diferentes contextos sociais através da Educação a Distância. Consolidando esse objetivo, espera-se que o $O$ Moodle de Lovelace seja uma referência de inclusão e de qualidade para a formação de programadoras no Estado do Espírito Santo e no Brasil.

\section{Recomendações pedagógicas para cursos de programação a distância}

Quanto às especificidades dos aspectos pedagógicos do curso Moodle de Lovelace, apresentam-se os princípios orientadores da produção da sala virtual e das ações dos professores e tutores. Buscou-se uma aproximação com a teoria de Vygotsky para criar condições de aprendizagem em uma perspectiva social [Vygotsky 1995, Rego 2013].

Entende-se que o aprendizado organizado está relacionado com o desenvolvimento e que, portanto, a aprendizagem traz possibilidades da modificação dos processos de desenvolvimento: "O aprendizado desperta processos de desenvolvimento que, aos poucos, vão tornar-se parte das funções psicológicas consolidadas do indivíduo" [Vygotsky 1995]. Para tal, busca-se que a mediação seja fomentada pela permanente interação por meio da tutoria afetiva. As atividades propostas para fins de processos de ensino mediados, através das possibilidades da sala virtual, trazem o foco nas ações do professor e dos colegas, em formas diversas de colaboração, de modo que o conhecimento da linguagem de programação, um signo, possa ser processualmente apreendido.

A Zona de Desenvolvimento Proximal (ZDP), conceito-chave para compreensão da relação entre ensino e aprendizagem [Vygotsky et al. 1984], relaciona-se com o desenvolvimento humano. "[...] refere-se ao caminho a ser percorrido para desenvolver funções que estão em processo de amadurecimento e que se tornarão funções consolidadas [...] ([Vygotsky 1995].

Apesar da relação com o desenvolvimento, entende-se que os conceitos e a dinâmica da ZDP não se referem apenas aos processos relacionados às faixas etárias, já que modificam-se nas sociedades, na História e nas relações subjetivas de cada sujeito e, por isso, têm possibilidades aplicáveis não apenas à infância. Entende-se, também, que a importância de aproximar o ensino de programação das meninas refere-se às formas especiais culturais nas quais elas foram alijadas de processos de ensino científico e

\footnotetext{
${ }^{1}$ Fonte: Jornal A Gazeta, 7 de Março de 20018
} 
tecnológicos. Dessa maneira, é preciso que os aspectos do ensino de programação considerem a aproximação dessa realidade, " [...] o ser humano, relacionando-se com o mundo e a coletividade onde vive, vai construindo o seu conhecimento através de uma interação mediada por diversas relações intra e interpessoais." [Veronezi et al. 2012].

A partir dessas considerações, buscou-se materializá-las em uma aproximação inicial a partir do diagnóstico geral das concepções dos sujeitos participantes; são disponibilizadas atividades para fins da visualização da aplicação de conceitos importantes para a programação - tal como lógica matemática - em tarefas que possibilitem o desempenho individual e a reprodução; por fim, atividades colaborativas e individuais, planejadas e replanejadas, para fins de contínuo processo de desenvolvimento por meio da aprendizagem. Ao longo de todas as semanas do curso de programação do Moodle de Lovelace, fóruns buscarão servir de local de concretude dos processos de mediação para fins de respostas a dúvidas, discussões, incentivos, afetividade e acompanhamento.

\section{O Moodle de Lovelace}

O Moodle de Lovelace é um curso a distância de Programação Python Essencial, Ativa e Prática direcionado para a formação de programadoras. Esse curso está sendo ofertado pelo Centro de Referência em Formação e Educação a Distância do Instituto Federal do Espírito Santo (Cefor/Ifes) e é pioneiro no estado do Espírito Santo.

Para a primeira turma do Moodle de Lovelace, foram aprovados 40 estudantes, incluindo jovens mulheres, mães, mulheres casadas e estudantes (meninas e meninos) que apóiam a chamada de meninas para as carreiras de computação. A Figura 1 apresenta a sala online do Moodle de Lovelace.

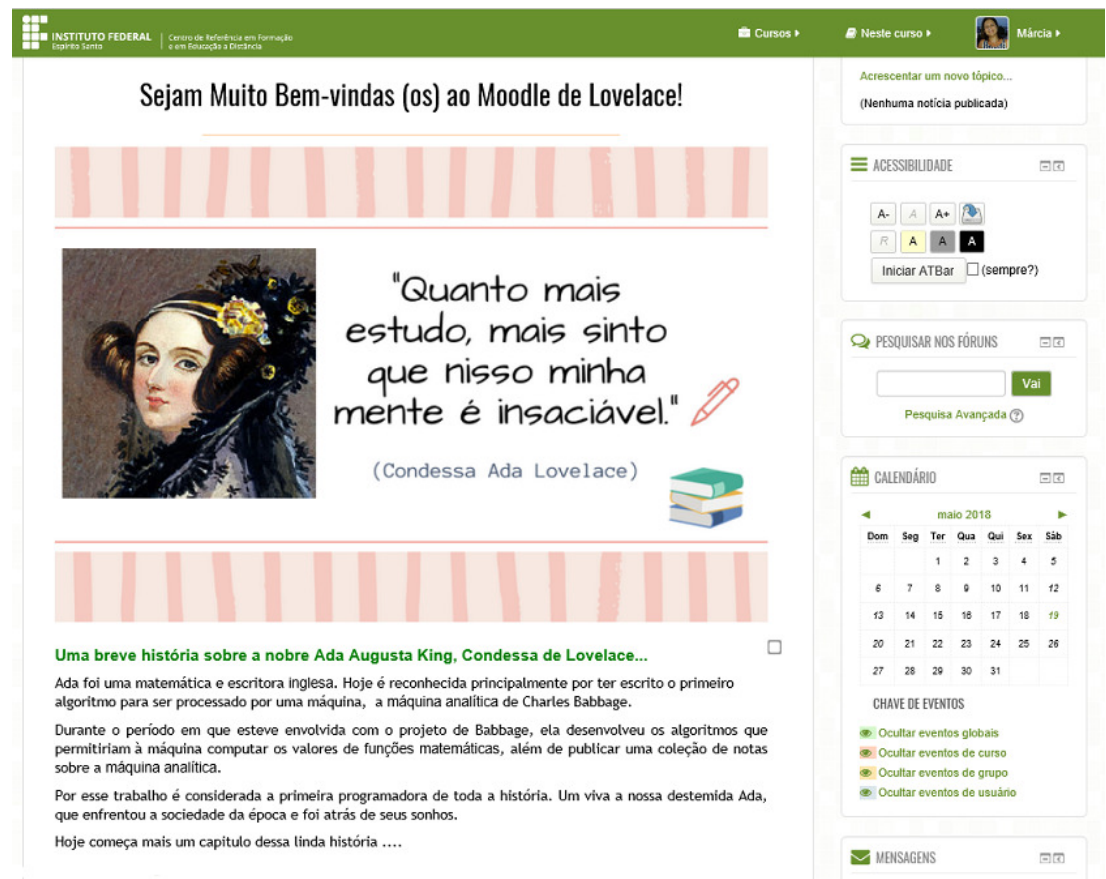

Figura 1. O Moodle de Lovelace: Curso de Programação Python

O objetivo geral do Moodle de Lovelace é formar programadoras a partir do desenvolvimento das habilidades envolvidas na prática da programação aplicando metodo- 
logias de aprendizagem ativa e tecnologias digitais de apoio ao processo educativo. Dessa forma, as metodologias ativas são aplicadas utilizando os próprios recursos do Moodle.

Os objetivos específicos do curso de Python são apresentar conceitos essenciais de programação, exercitar as habilidades de programação em atividades individuais e colaborativas e assistir a prática da programação por tutoria ativa e afetiva.

Os recursos tecnológicos utilizados no Moodle de Lovelace foram o Moodle, o ambiente Python Tutor ${ }^{2}$ para testes de programas, vídeos ilustrativos e vídeo-conferências. Além do Python tutor, foram indicadas no Moodle outras ferramentas para testes de programas escritos em Python e disponibilizados tutoriais para instalação de interpretadores Python para ambientes Windows e Linux. Dessa forma, fica a critério dos estudantes escolherem a ferramenta que considerarem mais adequada para testar seus programas.

Em cada unidade de conteúdos da ementa, isto é, em cada semana do curso, os conteúdos e as atividades são organizados da seguinte forma:

1. Apresentação de uma poesia em Python produzida com a colaboração do projeto Poesia Compilada [Andrade and Inácio Gomes Medeiros 2017].

2. Apresentação dos conteúdos e de exercícios resolvidos de forma visual, simples, atrativa e prática através de slides, vídeo-aulas e flashcards.

3. Fórum Sexto sentido, que é um fórum de discussão para as meninas darem palpites sobre a solução do exercício mais difícil da semana.

4. Quatro atividades práticas envolvendo habilidades da prática de programação: compreender, criar, analisar, revisar, observar, construir, refletir, associar, sequenciar e muitas outras, conforme [Antunes 2004].

5. Fórum Uma a outra ajudou, que é um fórum tira-dúvidas entre colegas aplicando as habilidades Perguntar, Ensinar e Colaborar. O fórum é realizado com perguntas e respostas com pontuação para quem faz perguntas relevantes e para quem ensina o colega a resolver um problema.

A Figura 2, apresenta como essa proposta metodológica foi aplicada na primeira semana do curso de Python do Moodle de Lovelace.

O projeto de aprendizagem a ser desenvolvido no final do curso deve sintetizar os conteúdos aprendidos e propor uma solução inovadora em Python para resolver um problema do mundo real.

Em resumo, todas as atividades da primeira semana e das demais semanas tiveram a finalidade de trabalhar habilidades essenciais na prática da programação e promover o trabalho colaborativo das meninas do Moodle de Lovelace.

\section{Conclusão}

Este trabalho apresentou $O$ Moodle de Lovelace como uma iniciativa baseada em metodologias ativas para ensinar programação a partir do desenvolvimento de habilidades. Destacamos que mesmo utilizando poucos recursos, é possível desenvolver um curso dinâmico com alta interação e ativa colaboração entre as alunas, tutoras e professoras.

Concluindo, o Moodle de Lovelace leva uma oportunidade de formação em programação às mulheres de diferentes contextos sociais, em especial para aquelas que

\footnotetext{
${ }^{2}$ Python Tutor: http://pythontutor.com
} 


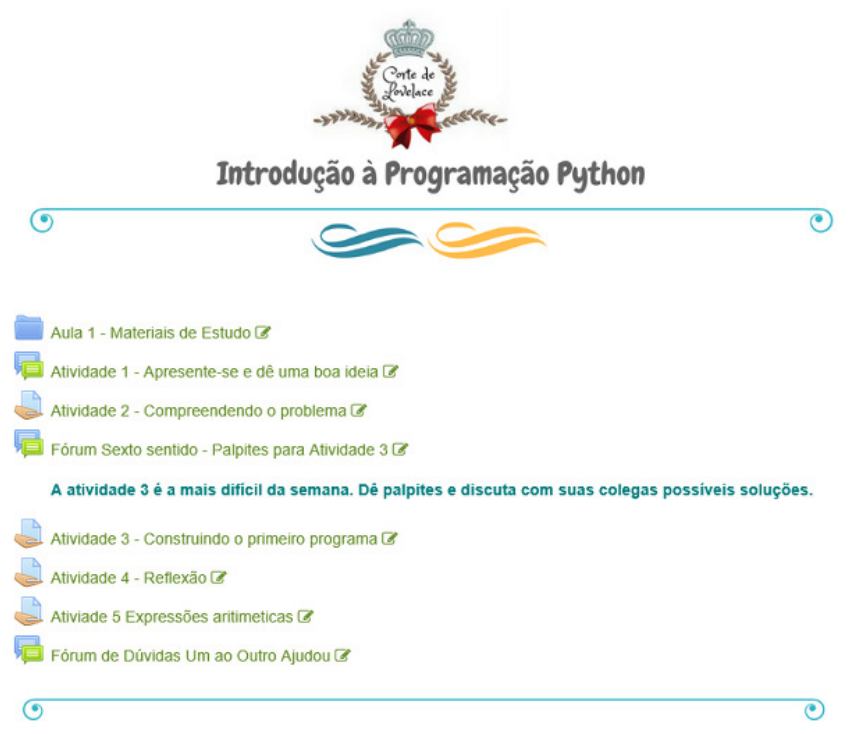

Figura 2. A primeira semana no Moodle de Lovelace

têm dificuldades em continuar estudos na modalidade presencial de ensino. Espera-se, portanto, que o Moodle de Lovelace contribua para a popularização da programação e para o resgate de uma maior participação feminina nas carreiras de computação.

\section{Referências}

Andrade, A. P. V. and Inácio Gomes Medeiros, S. R. (2017). Ensino de algoritmos com poesia compilada: experiências em turmas iniciais no bacharelado em sistemas de informação. In II Congresso sobre Tecnologias na Edução (CTRL-E).

Antunes, C. (2004). Trabalhando habilidades: construindo idéias. Scipione.

Moore, M. G. (2002). Teoria da distância transacional. Revista brasileira de aprendizagem aberta e a distância, 1(1).

Oliveira, M. G., Neves, A., Lopes, M. F. S., Medeiros, H. F., Andrade, M. B., and Reblin, L. L. (2017). Um curso de programação a distância com metodologias ativas e análise de aprendizagem por métricas de software. RENOTE, 15(1).

Rego, T. C. (2013). Vygotsky: uma perspectiva histórico-cultural da educação. Editora Vozes Limitada.

Souza, D. M., da Silva Batista, M. H., and Barbosa, E. F. (2016). Problemas e dificuldades no ensino e na aprendizagem de programação: Um mapeamento sistemático. Revista Brasileira de Informática na Educação, 24(1).

Veronezi, R. J. B., Damasceno, B. P., and Fernandes, Y. B. (2012). Funções psicológicas superiores: origem social e natureza mediada. Revista de Ciências Médicas, 14(6).

Vygotsky, L. S. et al. (1984). A formação social da mente.

Vygotsky, M. K. d. O. (1995). Aprendizado e desenvolvimento um processo sóciohistórico série pensamento e ação no magistério. São Paulo: Editora Scipione. 